\title{
The Influence of the MRSP on the Freezing and Evaporation Processes of the Magnesium Sulfate Subtype Salt Lake Brine
}

\author{
Qinghai Li, Kongjin Zhu, Yuntao Liu, Xingqiang Liu, Feng Li, Guoju Liu, Yong Yang, \\ Yonghua Li, Shenglin Liu, and Wenyi Song
}

China Bluestar Lehigh Engineering Corp., No. 51 Chaoyang West Road, Lianyungang, Jiangsu 222004, China

Correspondence should be addressed to Qinghai Li; liqinghai01@bluestar.chemchina.com

Received 9 May 2016; Revised 18 July 2016; Accepted 7 August 2016

Academic Editor: Tianlong Deng

Copyright ( 2016 Qinghai Li et al. This is an open access article distributed under the Creative Commons Attribution License, which permits unrestricted use, distribution, and reproduction in any medium, provided the original work is properly cited.

\begin{abstract}
We have developed a new concept, which is the mass fraction ratio of sulfate and potassium ions (MRSP), for the magnesium sulfate subtype salt lake, which is calculated using the metastable phase diagram. We also studied the trend of the MRSP values with the temperature and the influence of the MRSP values on the evaporation process. The experimental results indicated that the MRSP value showed significantly negative trend with decrease of refrigerated temperature. Moreover, when the MRSP value of the objective brine is reduced to less than or equal to the Specific Value by freezing operation, the great changes of crystal morphology and stage of $\mathrm{K}^{+}$and $\mathrm{SO}_{4}{ }^{2-}$ will take place, which makes the sequence of salts precipitation of the freezing-evaporation different from the direct-evaporation.
\end{abstract}

\section{Introduction}

Saline lakes are important mineral resources for national economy. China is famous for its large quantity, variety, and abundant rare elements of salt lakes [1]. Generally, according to the major elements compositions, the salt lake can be classified into five (or six) categories, that is, chloride type, sulfate type (includes magnesium sulfate subtype and sodium sulfate subtype), nitrite type, carbonate type, and borate type [2]. For magnesium sulfate subtype salt lake, depending on the proportion of $\mathrm{SO}_{4}{ }^{2-}$, the composition point of original brine always located in astrakhanite, schoenite, or sylvite region in the metastable phase diagram (MPD) of $\mathrm{Na}^{+}, \mathrm{K}^{+}$, $\mathrm{Mg}^{2+} / \mathrm{Cl}^{-}$, and $\mathrm{SO}_{4}{ }^{2-} / / \mathrm{H}_{2} \mathrm{O}$ at $25^{\circ} \mathrm{C}$ [3]. As a result, the varied double salts will precipitate during evaporation process of such salt lake brine [4]. For example, the potassium ions will precipitate in the form of schoenite, sylvite, and carnallite when the composition point is located in the schoenite region [5-7]. If the potash-bearing salts mixtures were used to produce potash fertilizer as raw materials, the process would be rather complex and the low yield of potassium ion would be obtained. Then, the diversified precipitations have unfavorable effect on the comprehensive utilization [8].
One way to solve this problem is freezing. The studies of brine freezing usually focus on precipitation pathway at subzero temperatures [9-11] and the desalination by freezing [12-16]. There is a potential application prospect of freezing desalination for salt lakes because saline lakes are generally distributed in high altitude and arid region with low temperature in winter.

Although previous studies indicated that the composition and crystallization paths could be optimized by means of freezing operation $[17,18]$, there are no effective methods to calculate and judge the degree of freezing operation.

This paper aims to explore the influences on the evaporative crystallization process for magnesium sulfate subtype brine by using freezing operation. A new concept, called the mass fraction ratio of sulfate and potassium ions (MRSP), was developed, which can be used to judge the degree of brine freezing. The results showed that the MRSP value had dropped from 7.93 to 3.46 when the brine was cooled from room temperature to $-5^{\circ} \mathrm{C}$. The astrakhanite and schoenite phase disappeared in the process of evaporative after being frozen, and the potassium ion precipitated in the form of sylvite and carnallite. Therefore, the suitable raw materials with the enhancement of the yield for potassium sulfate can be obtained. The results also demonstrated that the 
TABLE 1: Main chemical composition of the studied brine.

\begin{tabular}{lcccccccrrr}
\hline \multicolumn{2}{c}{ Sample number } & $\begin{array}{l}\text { Density } \\
\mathrm{g} \cdot \mathrm{cm}^{-3}\end{array}$ & $\mathrm{~K}^{+}$ & $\mathrm{Na}^{+}$ & $\mathrm{Mg}^{2+}$ & $\mathrm{Cl}^{-}$ & $\mathrm{SO}_{4}{ }^{2-}$ & $\mathrm{Li}^{+}$ & $\mathrm{CO}_{3}^{2-}$ & $\mathrm{HCO}_{3}{ }^{-}$ \\
\hline L0 & Original brine & 1.285 & 1.07 & 5.96 & 2.78 & 12.16 & 8.55 & 0.0081 & 0.17 & 0.051 \\
\hline
\end{tabular}

TABLE 2: Ionic composition (\%) of the studied brine samples, measured at different temperatures, and the index of phase diagram.

\begin{tabular}{|c|c|c|c|c|c|c|c|c|c|}
\hline \multirow{2}{*}{\multicolumn{2}{|c|}{ Sample number Refrigerated temperature ${ }^{\circ} \mathrm{C}$}} & \multicolumn{5}{|c|}{ Chemical composition $\%$} & \multicolumn{3}{|c|}{ Index of phase diagram } \\
\hline & & $\mathrm{K}^{+}$ & $\mathrm{Na}^{+}$ & $\mathrm{Mg}^{2+}$ & $\mathrm{Cl}^{-}$ & $\mathrm{SO}_{4}{ }^{2-}$ & $2 \mathrm{~K}$ & $\mathrm{Mg}$ & $\mathrm{SO}_{4}$ \\
\hline $\mathrm{L} 1$ & -18.0 & 1.48 & 3.14 & 3.71 & 16.05 & 1.55 & 9.05 & 83.24 & 7.71 \\
\hline $\mathrm{L} 2$ & -13.0 & 1.44 & 3.36 & 3.70 & 15.94 & 1.65 & 8.80 & 82.99 & 8.21 \\
\hline L3 & -5.0 & 1.30 & 4.40 & 3.34 & 14.20 & 4.20 & 7.66 & 72.21 & 20.14 \\
\hline
\end{tabular}

precipitation sequences of original and frozen brine were in accordance with MPD at $25^{\circ} \mathrm{C}$.

\section{Materials and Methodology}

Brine samples for the experiments were collected from a typical magnesium sulfate subtype salt lake from Qaidam Basin of China in summer. The major ionic chemical composition of the original brine is given in Table 1 .

$\mathrm{Na}^{+}, \mathrm{K}^{+}, \mathrm{Mg}^{2+}, \mathrm{Cl}^{-}$, and $\mathrm{SO}_{4}{ }^{2-}$ ions together contribute $99 \mathrm{wt} \%$ of the total. The MPD for the quinary system of $\mathrm{Na}^{+}, \mathrm{K}^{+}, \mathrm{Mg}^{2+}, \mathrm{Cl}^{-}$, and $\mathrm{SO}_{4}{ }^{2-}-\mathrm{H}_{2} \mathrm{O}$ can be suitable for predicting and explaining the concentration and crystallization behaviors of major elements in the objective brine [19].

This study includes freezing process and isothermal evaporation. For the freezing treatment, an enamel pail accompanied with original brines $(2.00 \mathrm{Kg})$ was stored in a refrigerating cabinet without stirring. The brine was cooled from ambient temperature to the setting subzero temperature and maintained for at least 24 hours. The solid was separated from the bittern quickly when the precipitation occurred. Besides, the samples were collected at subzero temperature. However, it is important to point out that the chemical analysis was conducted at ambient temperature.

The isothermal evaporation experiment was carried out in the lab. Concretely, the objective brine was stored in a plastic basin and in the meantime the brine temperature was regulated at $25^{\circ} \mathrm{C}$ by a mercury contact thermometer. An incandescent lamp was used to supply continuous heat and an electric fan was used as an air draft source. The new precipitation was taken three times per day, then examined, and analyzed by the polarizing microscope to identify the minerals phase. The solid and liquid phases should be separated when a new mineral phase precipitation occurred, and the relevant parameters such as complete chemical analysis of solid and liquid phases were then determined.

The following analytical methods were used [20]: $\mathrm{K}^{+}$and $\mathrm{Na}^{+}$were determined by flame atomic absorption spectrometry. $\mathrm{Mg}^{2+}$ was determined by complexometric titration with EDTA. $\mathrm{SO}_{4}{ }^{2-}$ was determined by barium sulfate gravimetric method and $\mathrm{Cl}^{-}$was analyzed by silver nitrate volumetric titration.
TABLE 3: Solid phase appearing in the phase diagram at $25^{\circ} \mathrm{C}$ involving the systems $\mathrm{Na}^{+}, \mathrm{K}^{+}, \mathrm{Mg}^{2+} / \mathrm{Cl}^{-}$, and $\mathrm{SO}_{4}{ }^{2-} / / \mathrm{H}_{2} \mathrm{O}$ with halite saturation throughout.

\begin{tabular}{lcc}
\hline Abbreviation & Salt mineral & Chemical formula \\
\hline Mir & Mirabilite & $\mathrm{Na}_{2} \mathrm{SO}_{4} \cdot 10 \mathrm{H}_{2} \mathrm{O}$ \\
Gla & Glaserite & $\mathrm{Na}_{2} \mathrm{SO}_{4} \cdot 3 \mathrm{~K}_{2} \mathrm{SO}_{4}$ \\
Sy & Sylvite & $\mathrm{KCl}$ \\
Pic & Schoenite & $\mathrm{K}_{2} \mathrm{SO}_{4} \cdot \mathrm{MgSO}_{4} \cdot 6 \mathrm{H}_{2} \mathrm{O}$ \\
Ast & Astrakhanite & $\mathrm{Na}_{2} \mathrm{SO}_{4} \cdot \mathrm{MgSO}_{4} \cdot 4 \mathrm{H}_{2} \mathrm{O}$ \\
Eps & Epsomite & $\mathrm{MgSO}_{4} \cdot 7 \mathrm{H}_{2} \mathrm{O}$ \\
Car & Carnallite & $\mathrm{KCl} \cdot \mathrm{MgCl}_{2} \cdot 6 \mathrm{H}_{2} \mathrm{O}$ \\
\hline
\end{tabular}

\section{Results and Discussion}

3.1. Freezing at Different Subzero Temperatures and Prediction of the Crystallization. During the experimental freezing progress, the original brine was refrigerated at $-18^{\circ} \mathrm{C},-13^{\circ} \mathrm{C}$, and $-5^{\circ} \mathrm{C}$, respectively. The analysis results for major ions of the studied brine at various temperatures are given in Table 2. The mineral salts involved in the diagram are summarized in Table 3. And the phase diagram points were drawn in the MPD of $\mathrm{Na}^{+}, \mathrm{K}^{+}, \mathrm{Mg}^{2+} / \mathrm{Cl}^{-}$, and $\mathrm{SO}_{4}{ }^{2-} / / \mathrm{H}_{2} \mathrm{O}$ at $25^{\circ} \mathrm{C}$ (Figure 1).

In Table 2 and Figure 1, the mass fraction of $\mathrm{SO}_{4}$ in brine decreased significantly as the temperature decreased, and the composition points of the liquid are all located on a straight line, extended from the tie line of the original brine composition point and the original point of $\mathrm{SO}_{4}$ on the triangular phase diagram. L0 is located in the astrakhanite region; L3 is located in epsomite region while L2 and L1 move to sylvite region. Then, the crystallization pathway of such kind of brines (L0 L4) can be predicted by using the location of coordinates on the MPD. Accordingly, if the solution reached the bischofite saturated point, the predicted precipitation should be present in sequences as in Table 4. It is assumed that the brine position remains constant during halite crystallization until the potash and magnesium sulfate bearing salts precipitation occur.

From Table 4, the kinds of predicted minerals of original brine (L0) were much more than L1, L2, and L3. Apparently, compared with L1, the astrakhanite and schoenite phases 


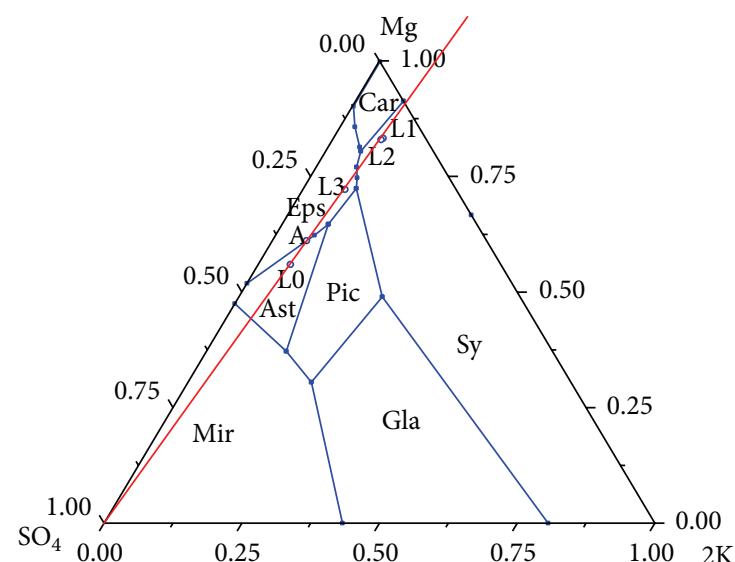

Figure 1: Location of the studied initial brine and liquid phase at different temperatures on the phase diagram at $25^{\circ} \mathrm{C}$ involving the system $\mathrm{Na}^{+}, \mathrm{K}^{+}, \mathrm{Mg}^{2+} / \mathrm{Cl}^{-}$, and $\mathrm{SO}_{4}{ }^{2-} / / \mathrm{H}_{2} \mathrm{O}$ with halite saturation throughout.

TABLE 4: The predicted sequences of the crystallization.

\begin{tabular}{lcc}
\hline L0 & L1 and L2 & L3 \\
\hline Halite & Halite & Halite \\
Halite + Ast & Halite + Sy & Halite + Eps \\
Halite + Pic + Eps & Halite + Car & Halite + Sy + Eps \\
Halite + Sy + Eps & Halite + Car + Eps & Halite + Car + Eps \\
Halite + Car + Eps & & \\
\hline
\end{tabular}

TABLE 5: The MRSP of L0 L3.

\begin{tabular}{lcc}
\hline Brine number & Temperature & MRSP \\
\hline L0 & Ambient & 7.99 \\
L1 & $-18.0^{\circ} \mathrm{C}$ & 1.05 \\
L2 & $-13.0^{\circ} \mathrm{C}$ & 1.15 \\
L3 & $-5.0^{\circ} \mathrm{C}$ & 3.23 \\
\hline
\end{tabular}

were absent in the sequence of L3, and potassium ion precipitated in the type of carnallite with epsomite in the later carnallite stage in the sequence of L1 and L2 because of the frozen operation.

From the conclusions we draw here, it is clear that temperature has a remarkable effect on the mass fraction of $\mathrm{SO}_{4}{ }^{2-}$ in the brine; meanwhile, the mass fraction of $\mathrm{SO}_{4}{ }^{2-}$ may have great influence on the distribution and crystal morphology of $\mathrm{K}^{+}$in the process of crystallization of salts. Therefore, the new concept of MRSP was developed, which can be used to describe the relationship between $\mathrm{K}^{+}$and $\mathrm{SO}_{4}{ }^{2-}$.

\subsection{Concept of MRSP. MRSP can be calculated by}

$$
\operatorname{MRSP}=\frac{\mathrm{SO}_{4} \%}{\mathrm{~K} \%} .
$$

The MRSP of L0 L3 are listed in Table 5.

From Table 5 and Figure 1, we can see that the value of MRSP starts to decline from 7.99 at ambient temperature to
TABLE 6: The chemical composition of the liquid phase formed by $25^{\circ} \mathrm{C}$-isothermal direct- and freezing-evaporation of brines.

\begin{tabular}{lcccccccc}
\hline $\begin{array}{l}\text { Sample } \\
\text { number }\end{array}$ & $\begin{array}{c}\text { Density } \\
\mathrm{g} \cdot \mathrm{cm}^{-3}\end{array}$ & \multicolumn{6}{c}{ Chemical composition\% } & \multirow{2}{*}{$\mathrm{MRSP}$} \\
\hline D-L0 & 1.285 & 1.07 & 5.96 & 2.78 & 12.16 & 8.55 & 69.47 & 7.99 \\
D-L1 & 1.298 & 1.25 & 5.75 & 3.17 & 12.33 & 9.34 & 68.15 & 7.47 \\
D-L2 & 1.306 & 1.88 & 3.99 & 4.21 & 13.32 & 8.72 & 67.87 & 4.64 \\
D-L3 & 1.309 & 2.09 & 3.31 & 4.48 & 13.76 & 8.07 & 68.27 & 3.86 \\
D-L4 & 1.328 & 2.33 & 1.63 & 5.92 & 15.69 & 7.05 & 67.36 & 3.03 \\
D-L5 & 1.322 & 2.18 & 1.47 & 5.77 & 16.76 & 5.30 & 68.49 & 2.43 \\
D-L6 & 1.334 & 1.80 & 0.78 & 6.63 & 18.66 & 5.06 & 67.03 & 2.81 \\
D-L7 & 1.335 & 0.71 & 0.43 & 7.48 & 19.85 & 3.94 & 67.55 & 5.55 \\
D-L8 & 1.365 & 0.19 & 0.22 & 8.61 & 22.23 & 3.41 & 65.28 & 17.95 \\
\hline F-L0 & 1.285 & 1.09 & 6.10 & 2.80 & 12.18 & 8.64 & 69.18 & 7.93 \\
F-L1 & 1.257 & 1.32 & 4.54 & 3.48 & 14.60 & 4.57 & 71.48 & 3.46 \\
F-L2 & 1.296 & 1.90 & 2.70 & 4.75 & 14.86 & 6.50 & 69.28 & 3.42 \\
F-L3 & 1.322 & 2.26 & 1.32 & 6.03 & 16.97 & 5.52 & 67.88 & 2.44 \\
F-L4 & 1.331 & 1.10 & 0.62 & 6.89 & 18.68 & 3.86 & 68.82 & 3.51 \\
F-L5 & 1.370 & 0.11 & 0.19 & 8.62 & 22.50 & 2.92 & 65.61 & 26.55 \\
\hline
\end{tabular}

1.05 at $-18.0^{\circ} \mathrm{C}$. Accordingly, the composition point moves to sylvite region from astrakhanite region across the epsomite $(\mathrm{L} 0 \rightarrow \mathrm{L} 1)$. Meanwhile, the kind of sulfates salts has been cut down in the predicted crystallization sequence; it is the absence of astrakhanite and picromerite. Hence, there should be a Specific MRSP value here. If the MRSP of the objective brine is greater than Specific MRSP, the brine should be frozen at subzero temperature to ensure that the MRSP should be less than the Specific MRSP. Actually, the Specific MRSP can be obtained by means of MPD of the $\mathrm{Na}^{+}, \mathrm{K}^{+}, \mathrm{Mg}^{2+} / \mathrm{Cl}^{-}$, and $\mathrm{SO}_{4}{ }^{2-} / / \mathrm{H}_{2} \mathrm{O}$. For example, in this study, through the analysis for phase diagram, a straight line connected the composition points of the original brine and the original point of $\mathrm{SO}_{4}$ cut the cosaturation line of astrakhanite and epsomite at point $\mathrm{A}$ (shown in Figure 1), in which the calculated MRSP value is 6.48. Therefore, the 6.48 value should be the Specific MRSP value for the studied brine. In other words, the MRSP of studied brine should be less than or equal to 6.48 by freezing methods.

3.3. Crystallized Sequences of Direct- and Freezing-Evaporation. To observe the changes of crystallization pathway of salt minerals after the MRSP was reduced, the direct-evaporation and freezing-evaporation experiments were carried out. The results including chemical composition of liquid and solid phase at $25^{\circ} \mathrm{C}$ are detailed in Table 6 . The crystallization pathway of brine at $25^{\circ} \mathrm{C}$ is shown in the quinary system phase diagram of $\mathrm{Na}^{+}, \mathrm{K}^{+}, \mathrm{Mg}^{2+} / \mathrm{Cl}^{-}$, and $\mathrm{SO}_{4}{ }^{2-} / / \mathrm{H}_{2} \mathrm{O}$ at $25^{\circ} \mathrm{C}$ (Figure 2).

There are seven solid phase regions saturated with $\mathrm{NaCl}$, including mirabilite, glaserite, sylvite, schoenite, astrakhanite, epsomite, and carnallite.

For the direct-evaporation experiment, the composition point of the objective original brine at $25^{\circ} \mathrm{C}$ is located in the 
TABLE 7: Composition of compounds for direct-evaporation crystallization.

\begin{tabular}{|c|c|c|c|c|c|c|c|c|}
\hline \multirow{2}{*}{ Stage } & \multicolumn{7}{|c|}{ Compounds composition $\%$} & \multirow{2}{*}{$\begin{array}{c}\text { Distribution of } \mathrm{K}^{+} \\
\%\end{array}$} \\
\hline & $\mathrm{NaCl}$ & $\mathrm{KCl}$ & $\mathrm{MgCl}_{2}$ & $\mathrm{Na}_{2} \mathrm{SO}_{4}$ & $\mathrm{MgSO}_{4}$ & $\mathrm{~K}_{2} \mathrm{SO}_{4}$ & $\mathrm{H}_{2} \mathrm{O}$ & \\
\hline Halite & 62.57 & - & - & 8.83 & 9.71 & 0.76 & 18.13 & 1.06 \\
\hline Ast & 43.20 & - & - & 17.87 & 20.11 & 0.71 & 18.10 & 4.43 \\
\hline \multicolumn{9}{|c|}{ Mixed potassium } \\
\hline Pic & 33.51 & - & - & - & 26.45 & 5.75 & 33.29 & 38.89 \\
\hline Sy & 27.29 & 17.58 & 3.98 & - & 21.23 & - & 29.92 & 18.45 \\
\hline Car & 8.39 & 15.88 & 17.49 & - & 20.64 & - & 37.60 & 34.59 \\
\hline
\end{tabular}

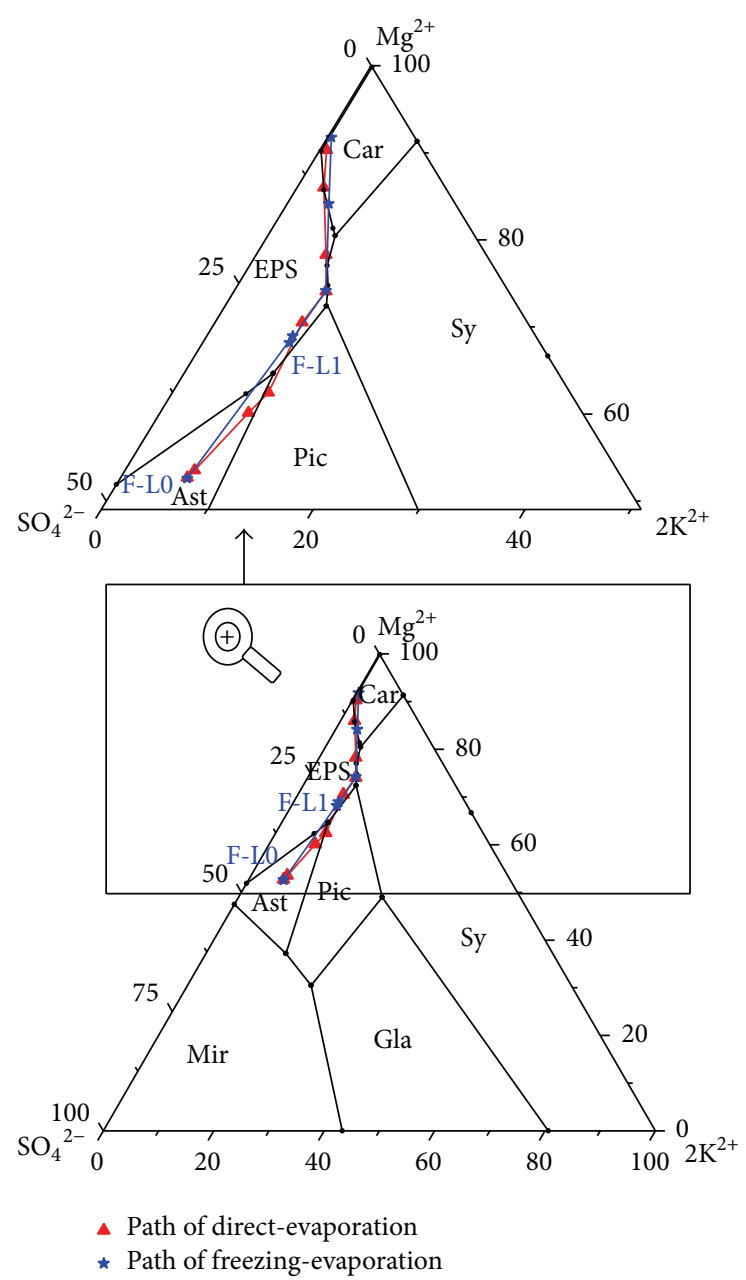

FIGURE 2: Graphical representations of the evaporation pathway on the MPD at $25^{\circ} \mathrm{C}$ showing (red triangle) direct-evaporation crystallization and (blue star) freezing-evaporation crystallization.

astrakhanite region. Because most of the salts are $\mathrm{NaCl}$, halite crystallized immediately after the beginning of isothermal evaporation. The second salt that precipitated is astrakhanite. The composition point of the liquid phase mainly follows the path from the original brine composition point to the astrakhanite solid phase point, where halite and astrakhanite are the principal precipitated salts, then followed by schoenite together with halite and epsomite. Hence, sylvite saturation is achieved, and the precipitation processes of sylvite and

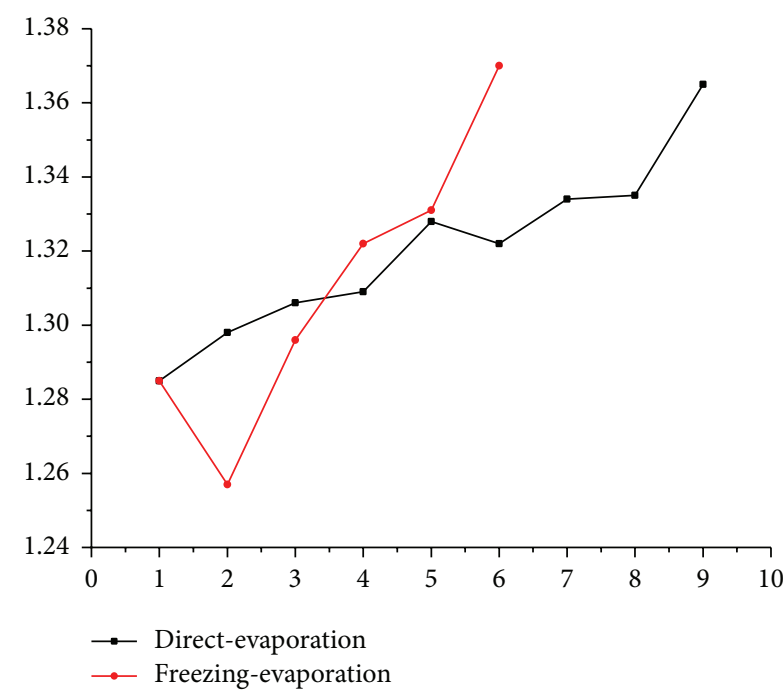

Figure 3: The changing trend of density in the process of two evaporations.

epsomite have been accomplished. Large amounts of carnallite start to precipitate with some epsomite during the late period of experiment. The sequence of mineral precipitation from the brine at $25^{\circ} \mathrm{C}$ is in accordance with the summary listed in Table 3.

For the freezing-evaporation experiment, the original brine composition point moves to epsomite from astrakhanite region (F-L0 to F-L1), and the MRSP value has dropped from 7.93 to 3.46 (less than the Specific MRSP value 6.48) after freezing at $-5^{\circ} \mathrm{C}$. The second saturated and precipitated salt is epsomite instead of astrakhanite. The pathway of freezingevaporation is the same with the direct-evaporation pathway after the saturation of sylvite.

The results also show that both the precipitation sequences are in good agreement with MPD at $25^{\circ} \mathrm{C}$.

Based on the results of our experiments, the entire evaporation process could be divided into five basic stages and composition of compounds are listed in Tables 7 and 8, respectively, for direct-evaporation and freezing -evaporation crystallization (composition of compounds is ore matching based on the ion analysis results).

According to the data in Tables 7 and 8, the difference in compounds composition between the direct-evaporation and freezing-evaporation experiments lies in the crystallization 
TABLE 8: Composition of compounds for freezing-evaporation crystallization.

\begin{tabular}{|c|c|c|c|c|c|c|c|c|}
\hline \multirow{2}{*}{ Stage } & \multicolumn{7}{|c|}{ Compounds composition $\%$} & \multirow{2}{*}{$\begin{array}{c}\text { Distribution of } \mathrm{K}^{+} \\
\%\end{array}$} \\
\hline & $\mathrm{NaCl}$ & $\mathrm{KCl}$ & $\mathrm{MgCl}_{2}$ & $\mathrm{Na}_{2} \mathrm{SO}_{4}$ & $\mathrm{MgSO}_{4}$ & $\mathrm{~K}_{2} \mathrm{SO}_{4}$ & $\mathrm{H}_{2} \mathrm{O}$ & \\
\hline Mir & 2.80 & - & - & 37.86 & 1.88 & 0.31 & 57.15 & 2.28 \\
\hline Halite & 92.02 & 0.46 & 1.04 & - & 0.86 & - & 5.62 & 1.33 \\
\hline \multicolumn{9}{|c|}{ Mixed potassium } \\
\hline Eps & 35.46 & 5.43 & 1.67 & - & 25.19 & - & 32.25 & 19.29 \\
\hline Sy & 11.13 & 14.70 & 13.04 & - & 21.21 & - & 39.90 & 49.34 \\
\hline Car & 7.17 & 11.92 & 24.05 & - & 12.44 & - & 44.37 & 24.71 \\
\hline
\end{tabular}

type and stage of $\mathrm{K}^{+}$and $\mathrm{SO}_{4}{ }^{2-}$. For the direct-evaporation, the distribution of potassium ion in picromerite, sylvine, and carnallite stages was about $91.93 \%$. That is to say, most of the potassium ions precipitated in the forms of $\mathrm{K}_{2} \mathrm{SO}_{4} \cdot \mathrm{MgSO}_{4} \cdot 6 \mathrm{H}_{2} \mathrm{O}, \mathrm{KCl}$, and $\mathrm{KCl} \cdot \mathrm{MgCl}_{2} \cdot 6 \mathrm{H}_{2} \mathrm{O}$. On the other hand, $\mathrm{SO}_{4}{ }^{2-}$ always precipitated in the different forms of double salts at different stages, such as double salts $\mathrm{Na}_{2} \mathrm{SO}_{4}$ and $\mathrm{MgSO}_{4}$ at the astrakhanite stage, double salts $\mathrm{K}_{2} \mathrm{SO}_{4}$ and $\mathrm{MgSO}_{4}$ when the picromerite is saturated, or epsomite at the sylvite and carnallite stage.

For the freezing-evaporation, a large amount of $\mathrm{SO}_{4}{ }^{2-}$ precipitated at the low temperature in the freezing mirabilite stage, and some $\mathrm{SO}_{4}{ }^{2-}$ in the residual brine precipitated in the form of mirabilite and double salt or hydrated salt of magnesium sulfate through the evaporation process. $\mathrm{K}^{+}$ precipitated only in the form of $\mathrm{KCl}$ over the entire isothermal evaporation process.

Through the comparative analysis of the two tables, we can find that the crystallization type and stage of $\mathrm{K}^{+}$and $\mathrm{SO}_{4}{ }^{2-}$ have changed significantly with the decrease of MRSP value. Therefore, the MRSP will be an important parameter, which can be used to estimate the composition of the salt lake brine.

3.4. Trend of the Density. Figure 3 presents the changing trend of density in the process of two evaporations. For freezing-evaporation, as the program went on, the density increased initially and then reduced. And for direct-freezing, the density increased from beginning to end. The variational trend was also found in MRSP value.

\section{Conclusions}

The following conclusions are drawn based on the experiments at subzero temperature and $25^{\circ} \mathrm{C}$. The content of $\mathrm{SO}_{4}{ }^{2-}$ in brines has decreasing trend with the decreasing of temperature; in other words, the MRSP was decreased. The Specific Value of MRSP can be calculated using the composition point coordinates and the metastable phase diagram relating to the $\mathrm{Na}^{+}, \mathrm{K}^{+}, \mathrm{Mg}^{2+}, \mathrm{Cl}^{-}, \mathrm{SO}_{4}{ }^{2-}$, and $\mathrm{H}_{2} \mathrm{O}$ system. If the MRSP in the objective brine is higher than Specific Value, the brine should be frozen at subzero temperature to ensure that the MRSP keeps less than the Specific Value. Both predicted and experimental sequences of the evaporation process demonstrated that the great changes of crystal morphology and stage of $\mathrm{K}^{+}$and $\mathrm{SO}_{4}{ }^{2-}$ had taken place after the decrease of MRSP. As a concrete manifestation of the absence of astrakhanite and picromerite minerals and the simplification of $\mathrm{K}^{+}$crystallized forms and so forth, the MRSP thus would be important reference information to judge the composition of the brine for the comprehensive utilization.

\section{Additional Points}

Highlights. (1) Put forward a new concept MRSP and Specific MRSP and present the calculating methods using the metastable phase diagram. (2) The trend of the MRSP values with the decreasing temperature and the influence of the decreased MRSP values on the evaporation process were studied. (3) The differences of crystal morphology and stage of $\mathrm{K}^{+}$and $\mathrm{SO}_{4}{ }^{2-}$ were described between the conditions of the MRSP value which was decreased and not.

\section{Competing Interests}

The authors declare that there are no competing interests regarding the publication of this article.

\section{Acknowledgments}

The authors are thankful to China Bluestar Lehigh Engineering Corp. for providing financial support to this study. The authors would like to express gratitude to the Minmetals Salt Lake Co. Ltd. for the brine samples offering. The authors also extend special thanks to Dr. Genping Huang, Tianjin University, for his help to this article.

\section{References}

[1] X. Y. Zheng, M. G. Zhang, Ch. Xu, and B. X. Li, Chinese Salt Lake, Science Press, Beijing, China, 2002.

[2] S. Y. Gao, P. S. Song, S. P. Xia, and M. P. Zheng, Salt Lake Chemistry-A New Type of Lithium and Boron Salt Lake, Science Press, 2007.

[3] Z. M. Jin, X. Zh. Xiao, and Sh. M. Liang, "Study of the metastable equilibrium for pentanary system of $\left(\mathrm{Na}^{+}, \mathrm{K}^{+}, \mathrm{Mg}^{2+}\right),\left(\mathrm{Cl}^{-}\right.$, $\mathrm{SO}^{2-}, \mathrm{H}_{2} \mathrm{O}$," Acta Chimica Sinica, vol. 4, pp. 313-320, 1980.

[4] H. Hammi, J. Musso, A. M'nif, and R. Rokbani, "Crystallization path of natural brine evaporation using the DPAO method," Desalination, vol. 166, no. 1-3, pp. 205-208, 2004. 
[5] X. M. Cui, Z. Wu, X. Wen, and X. Zhang, "Simulated dynamic evaporation of yiliping salt lake brine," Acta Geologica Sinica, vol. 88, pp. 305-306, 2014.

[6] M. S. M. Abdel Wahed, E. A. Mohamed, M. I. El-Sayed, A. M’nif, and M. Sillanpää, "Crystallization sequence during evaporation of a high concentrated brine involving the system $\mathrm{Na}-\mathrm{K}-\mathrm{Mg}-$ Cl-SO $\mathrm{SO}_{4}-\mathrm{H}_{2} \mathrm{O}$," Desalination, vol. 355, pp. 11-21, 2015.

[7] S. Attia-Essaies, L. Zayani, D. B. H. Chehimi, R. C. Adad, N. K. Ariguib, and M. Trabelsi-Ayadi, "Simulation of crystallization sequence during the evaporation of Chott El Jerid brine (South Tunisia)," Thermochimica Acta, vol. 503-504, no. 1, pp. 8-11, 2010.

[8] Q. L. Zhu and X. L. Huang, "Process in the study of freezing process for salt lake brine," Tianjin Chemical Industry, vol. 3, pp. $1-4,2015$.

[9] T. G. Thompson and K. H. Nelson, "Concentration of brines and deposition of salts from sea water under frigid conditions," American Journal of Science, vol. 254, no. 4, pp. 227-238, 1956.

[10] G. M. Marion, R. E. Farren, and A. J. Komrowski, "Alternative pathways for seawater freezing," Cold Regions Science and Technology, vol. 29, no. 3, pp. 259-266, 1999.

[11] Q.-H. Li, T.-X. Gu, S.-S. Yu, Y. Yao, B. Li, and W. Li, "Study on the precipitation pathway of Nanyishan oil field brine at subzero temperatures," Acta Physico-Chimica Sinica, vol. 27, no. 8, pp. 1803-1808, 2011.

[12] W. E. Johnson, "State-of-the-art of freezing processes, their potential and future," Desalination, vol. 19, no. 1-3, pp. 349-358, 1976.

[13] J. A. Heist, "Freeze crystallization," Chemical Engineering, vol. 86, no. 10, pp. 72-82, 1979.

[14] P. L. T. Brian, "Potential advantages and development problems in water desalination by freezing," Chemical Engineer, vol. 78, pp. 191-197, 1971.

[15] W. E. Johnson, "Indirect freezing," Desalination, vol. 31, no. 1-3, pp. 417-425, 1979.

[16] S. M. Badawy, "Laboratory freezing desalination of seawater," Desalination and Water Treatment, vol. 57, no. 24, pp. 1104011047, 2015.

[17] Z. Fu, Z. Zhang, Y. Ma, S. Dong, J. Zhu, and Z. Yan, "Freeze sulfate-type brine at low temperature in stages and theoretical study on evaporation and crystallization behavior," Inorganic Chemicals Industry, vol. 2, pp. 29-32, 2013.

[18] Z.-M. Wu, M.-P. Zheng, X.-F. Liu, and Z. Nie, "Concentration of brines from the Dogai Coring Lake, Northern Tibet, by using the two-step process: freezing and solar evaporation," Chinese Journal of Inorganic Chemistry, vol. 28, no. 5, pp. 995-1000, 2012.

[19] T. L. Deng, H. Zhou, and X. Chen, Salt-Water System Phase Diagrams and Applications, Chemical Industry Press, Beijing, China, 2013.

[20] American Public Health Association (APHA), Standard Methods for the Examination of Water and Waste Water, American Public Health Association, Washington, DC, USA, 20th edition, 1998. 

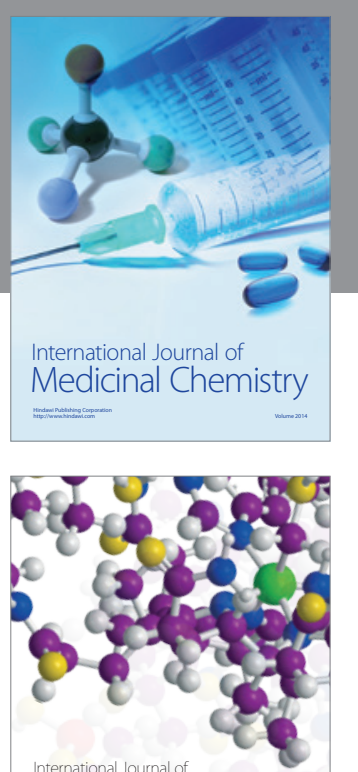

Carbohydrate Chemistry

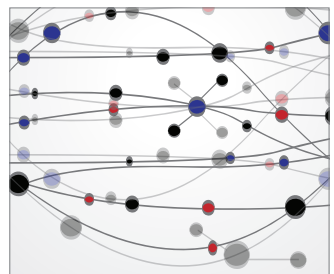

The Scientific World Journal
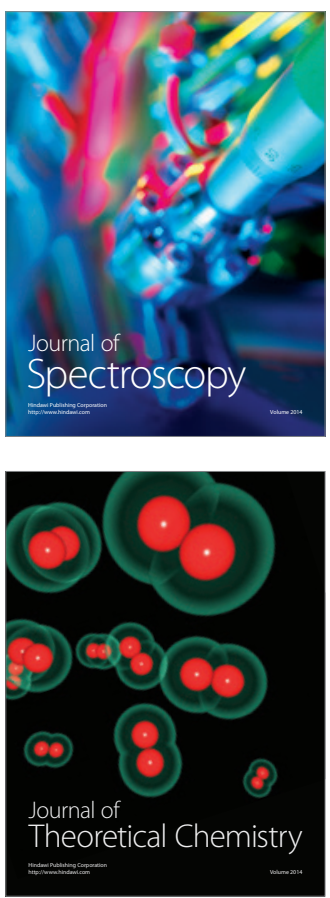
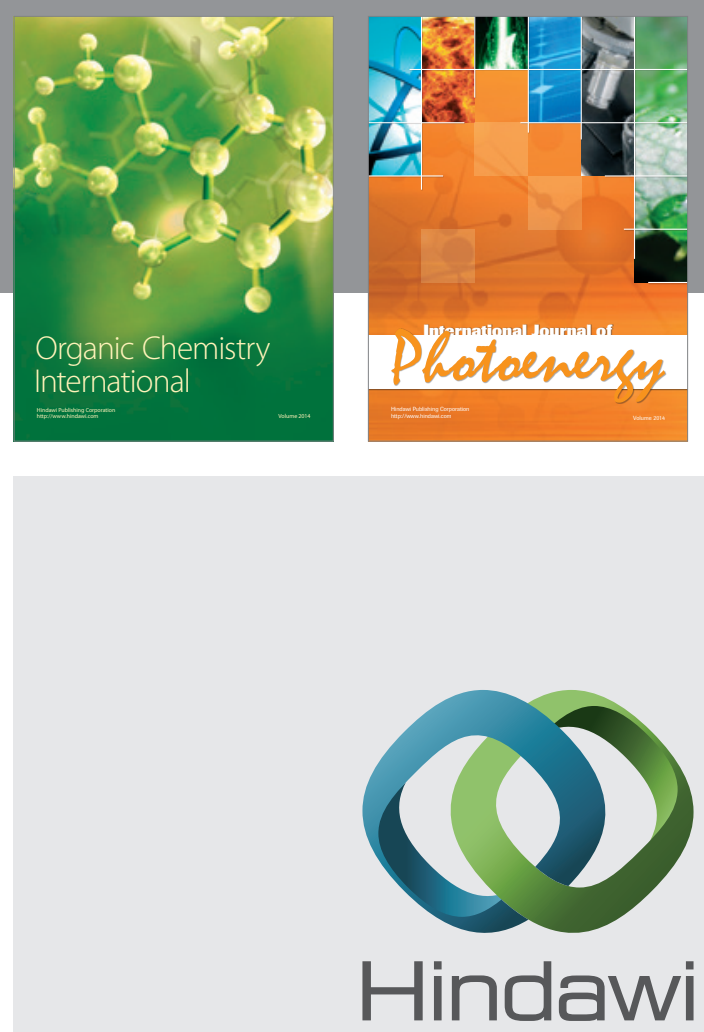

Submit your manuscripts at

http://www.hindawi.com

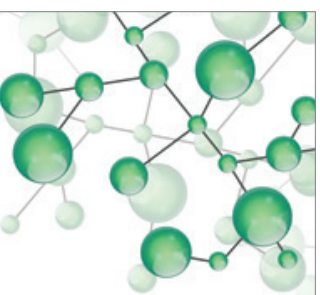

International Journal of

Inorganic Chemistry

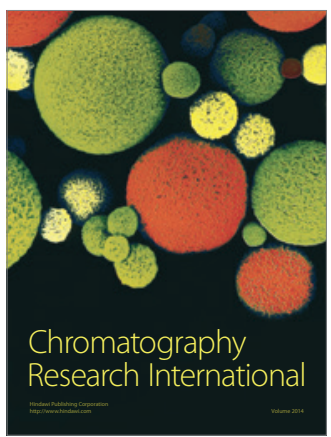

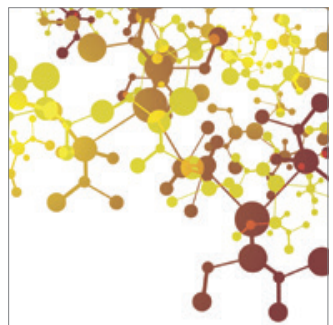

Applied Chemistry
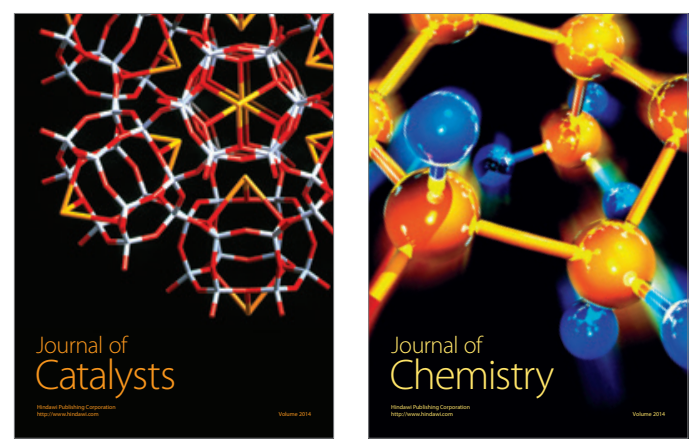
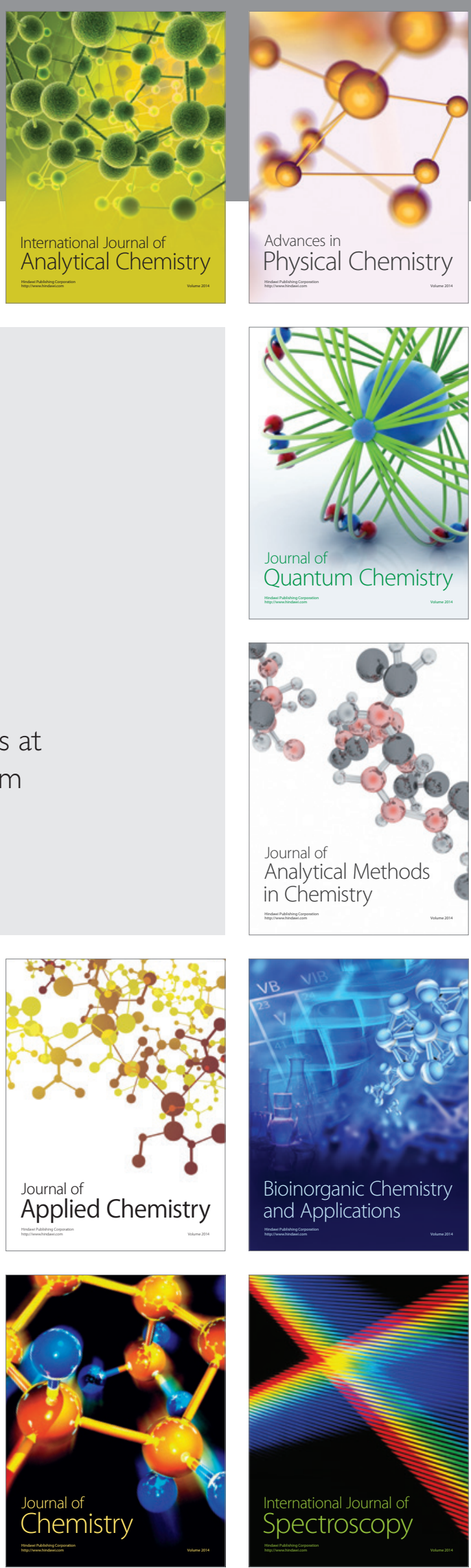